\title{
Immediate and Short-term Changes in Left Ventricular Function in Children Undergoing Percutaneous Closure of Patent Ductus Arteriosus by Echocardiography and Tissue Doppler \\ Hebatallah M. Attia, Dina A.E. EI Din, Ahmed M. Hassan
}

Department of Cardiology, Faculty of Medicine, Ain Shams University

dr.ahmed.magdy@aol.com

\begin{abstract}
Background: Patent ductus arteriosus accounts for 5-10\% of all congenital heart diseases. Left-to-right shunting through the PDA results in pulmonary over-circulation and left heart volume overload. Transcatheter closure is the method of choice for PDA closure when suitable. Some previous studies have described an immediate deterioration of left ventricular functions after percutaneous closure of PDA, which is reversible and improves after few months. Purpose: This study aimed to determine the immediate and short-term changes in the left ventricular function in children with patent ductus arteriosus after percutaneous closure using 2D echocardiography and tissue doppler imaging. Patients and Methods: Thirty children with isolated PDA were treated by trans-catheter closure were studied. The LV dimensions, volumes and systolic function were assessed by two-dimensional echocardiography and tissue Doppler imaging before the PDA closure, on day 1 and after one month. Results: The median age of the patients was 4.25 years and mean BSA was $0.73 \pm$ $0.31 \mathrm{~m}^{2}$, with the mean PDA diameter of $2.53 \pm 0.60 \mathrm{~mm}$. The LVEDD, LVESD, left atrium diameter, ejection fraction and LVEDV reduced significantly immediately after PDA closure $(p<0.001)$. After 1 month, LVEDD, LVESD and LAD continued to decrease, while ejection fraction improved significantly. All tissue Doppler velocities showed a significant decrease immediately after closure with significant increase of MPI ( $p$ $<0.001$ ) and then were improved within 1 month. Conclusion: percutaneous closure of PDA was associated with reversible significant decrease in the left ventricular systolic and diastolic functions, which recovered after one month.
\end{abstract}

Keywords: Left ventricular function, Echocardiography and tissue Doppler, Patent ductus arteriosus

\section{INTRODUCTION}

The ductus arteriosus is a fetal communication between the descending aorta just distal to the left subclavian artery and the main pulmonary artery near its bifurcation. It is a normal and essential component of the fetal circulation as it allows right-to-left shunting of nutrient-rich, oxygenated blood from placenta to the fetal systemic circulation, thereby bypassing the fetal pulmonary circuit. In the fetus the ductus arteriosus is kept open by low arterial oxygen content and placental prostaglandin E2 (PGE2). At birth, several changes occur to initiate closure of the ductus arteriosus within the first 15 to 18 hours of life and completely closed by 2 to 3 weeks. Spontaneous closure of a PDA is unlikely to occur in term infants after 3 months and in preterm infants after 12 months ${ }^{(1)}$.

Patent ductus arteriosus is one of the most common congenital heart defects, accounting for 5$10 \%$ of all congenital heart diseases in term infants with incidence of 1 in 2000 births. Incidence of PDA is greater in preterm infants and more common among females than males with ratio of $2: 1$. Several risk factors have been shown to increase the incidence of PDA, including high altitude birth, genetic factors and maternal rubella infection. Clinical signs of ductal patency may include continuous murmur, tachycardia, bounding peripheral pulses and symptoms and signs of congestive heart failure $^{(2)}$.

The echocardiogram is the procedure of choice to confirm the diagnosis and to characterize a PDA. In addition to evaluating the ductus arteriosus, the echocardiogram is used to identify and evaluate other associated cardiac defects. M-mode echocardiography is used to measure the cardiac chamber sizes and quantitate left ventricular systolic function. Two-dimensional imaging demonstrates the geometry of the ductus. Color Doppler is a very sensitive modality in detecting the presence of a PDA and is frequently used to estimate the degree of ductal shunting ${ }^{(3)}$.

Transcatheter closure is widely considered as the treatment of choice for patients diagnosed with PDA since the first experience of the transcatheter occlusion of PDA by Porstmann et al. in $1971^{(4)}$. It is performed using various devices, such as detachable coils, Nit-Occluders and Amplatzer duct occluder. Previous studies have reported an immediate change in LV performance followed by recovery within a few months after successful transcatheter closure of PDAs in children ${ }^{(5)}$. Hemodynamically significant PDA, once closed, decreases the preload to the LV by abolishing the left-to-right shunt and increases the afterload by isolating the low-resistance pulmonary circulation from LV outflow circulation. This simultaneous reduction in the LV preload and 
increase in the afterload may lead to LV systolic dysfunction ${ }^{(6)}$.

The alteration in left ventricular function before and after PDA closure seems interesting to study using tissue doppler to detect myocardial velocities and evaluate subtle left ventricular dysfunction following PDA closure.

\section{PATIENTS AND METHODS}

The study included thirty patients with PDA who were referred for elective percutaneous closure in Ain Shams University Hospital from January 2016 to March 2018. The study was approved by the Ethics Board of Ain Shams University.

The inclusion criteria: The study included children with isolated PDA which is hemodynamically significant and suitable for percutaneous closure.

The exclusion criteria: Cases of silent PDA, cases of PDA which is not suitable for percutaneous closure, associated with other hemodynamically significant cardiac lesions, irreversible pulmonary vascular disease or significant residual shunt were excluded from the study.

All patients were subjected to the following:

1- History and clinical examination.

2- Routine investigations: Routine investigations prior to cardiac catheterization including. Echocardiography: (Pre-closure, immediately after closure and 1 month follow up).

3- Echocardiogram was performed using Phillips iE33 echocardiography machine to assess the following:

The left ventricular dimensions and functions was assessed by M-mode and Simpson's method measuring the LV ejection fraction, LV end diastolic volume and LV end systolic volume. The M-mode was used to estimate the LVEDD and LVESD by applying the m-mode to the LV just below the mitral valve in a parasternal long axis view. The left ventricular dilatation was used as a useful marker for assessing the magnitude of shunting. A dilated and hyper-dynamic left side of the heart was an indication of volume overload after correlating the dimensions with the patient's age ${ }^{(7)}$.

The left atrial diameter was assessed by applying the m-mode to the LA and Aorta in the parasternal long axis view.

PDA: The assessment of the PDA was done from the parasternal short axis view, ductal view and suprasternal view using 2D echocardiography, color flow mapping and doppler to evaluate the size, length and shape of the ductus and to assess the diameter of the ampulla and the pulmonary end. The ductal view was obtained by imaging one intercostal space higher than the standard parasternal short axis, with slight leftward and anterior angulation of the scan plane (toward the left shoulder) and counter-clockwise rotation of the transducer. Peak pressure gradient (PPG) across the PDA using continuous wave Doppler was recorded.

Myocardial performance index (MPI) or Tei index: It was calculated from the ratio of time intervals $(a-b / b)$ derived with the aid of pulsed doppler. Locating the sample volume at the tips of the mitral valve leaflets in the apical 4-chambers view enabled the measurement of "a", which is the time interval between the end and the start of transmitral flow. The sample volume was then located in the LV outflow tract just below the aortic valve in the apical 5-chambers view for the assessment of "b", which represents the LV ejection time. The interval "a" includes the isovolumic contraction time (IVCT), the ejection time (ET) and the isovolumic relaxation time (IVRT), and the Tei index may also be expressed by the formula IVCT+IVRT/ET ${ }^{(9,10)}$.

\section{4- Tissue Doppler imaging (TDI):}

After the 2D study, tissue Doppler imaging was used to evaluate the LV velocities by PW Doppler at lateral and septal MV annulus in apical 4chamber view. Peak systolic annular velocity (S), peak early diastolic annular velocity(A) and peak late diastolic annular velocity (E) were recorded pre closure of the ductus, immediately after closure and after one month to evaluate changes in LV systolic and diastolic functions (figure 1) ${ }^{(7)}$.

\section{Cardiac catheterization:}

All patients enrolled in the study underwent safe cardiac catheterization and successful percutaneous closure of PDA after performing echocardiography. All parents signed an informed consent before the procedure.

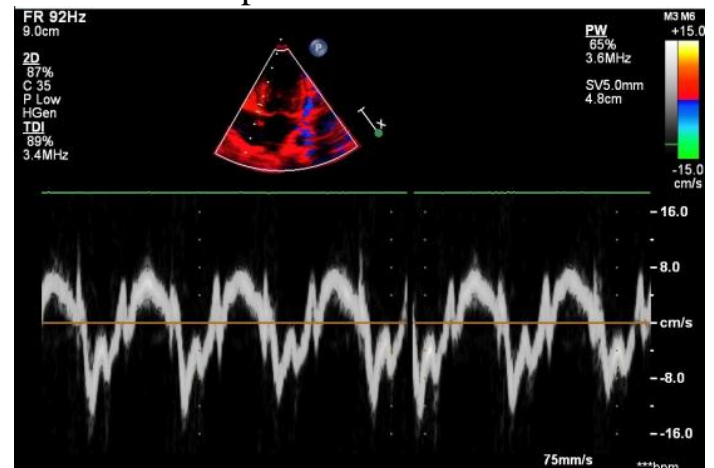

Figure (1): TDI by applying PW Doppler at septal mitral annulus immediately after PDA closure 


\section{RESULTS}

\section{Patient characteristics:}

The patients were 14 males (46.7\%) and 16 females $(53.3 \%)$, with a median age of 4.25 years ranging from 0.6 to 16 years and IQR ranging from 1.5 to 7 years.

The patient's body surface area was ranged from 0.35 to $1.6 \mathrm{~m}^{2}$ with a mean BSA of $0.73 \pm 0.31$ $\mathrm{m}^{2}$, their weight ranged from 6.8 to $56 \mathrm{~kg}$ with a median of $17 \mathrm{~kg}$ and an IQR from 11 to $23 \mathrm{~kg}$ and their height ranged from 65 to $164 \mathrm{~cm}$ with a mean of $101.73 \pm 26.02 \mathrm{~cm}$. The mean heart rate of the patients was $111.60 \pm 27.14 \mathrm{bpm}$ pre-closure, 121.17 $\pm 22.39 \mathrm{bpm}$ immediately after closure of the PDA and $100.80 \pm 19.36 \mathrm{bpm}$ after one month.

Trans-catheter closure of the PDAs was done using a coil in 23 cases (76.7 \%), while using a device in 7 cases (23.3).

2D and Doppler echocardiographic assessment before and immediately after PDA closure:

\section{PDA assessment:}

The PDA size (pulmonary end) ranged from 1.7 to $4 \mathrm{~mm}$ with a mean of $2.53 \pm 0.60 \mathrm{~mm}$, the PDA ampulla ranged from 4 to $11 \mathrm{~mm}$ with a mean of $5.85 \pm 1.35 \mathrm{~mm}$, PPG across the ductus ranged from 48 to $120 \mathrm{mmHg}$ with a mean of $82.6 \pm 18.08$ $\mathrm{mmHg}$, the DPG across the ductus ranged from 16 to $55 \mathrm{mmHg}$ with a mean of $30 \pm 9.75 \mathrm{mmHg}$.

\section{End Diastolic Dimensions (LVEDD):}

The LV end diastolic dimensions decreased significantly after successful PDA closure, the mean LVEDD before PDA closure was $35.50 \pm 7.15 \mathrm{~mm}$ which decreased to $32.80 \pm 7.07 \mathrm{~mm}$ after PDA closure ( $\mathrm{P}$ value 0.001) (Table 1). The LV end diastolic dimensions indexed to BSA also decreased significantly after successful PDA closure, the mean LVEDDI decreased from $53.69 \pm 13.44 \mathrm{~mm} / \mathrm{m}^{2}$ before closure to $50.29 \pm 11.24 \mathrm{~mm} / \mathrm{m}^{2}$ immediately after PDA closure (P value 0.005) (Table 2\& figure 2).

\section{End Systolic Dimensions (LVESD):}

The LV end systolic dimensions decreased significantly after successful PDA closure, the mean LVESD before PDA closure was $23.27 \pm 5.54 \mathrm{~mm}$ which decreased to $22.50 \pm 5.81 \mathrm{~mm}$ after PDA closure (P value 0.001) (Table 2).

The LV end systolic dimensions indexed to BSA showed a non significant decrease from $36.10 \pm$ $10.82 \mathrm{~mm} / \mathrm{m}^{2}$ before PDA closure to $33.27 \pm 6.82$ $\mathrm{mm} / \mathrm{m}^{2}$ after PDA closure (P value 0.065 ) (Table 2) (Figure 2).

\section{End Diastolic Volume (LVEDV):}

The LV end diastolic volume decreased significantly after successful PDA closure, the mean LVEDV before PDA closure was $40.40 \pm 22.58 \mathrm{ml}$ which decreased to $39.07 \pm 22.11 \mathrm{ml}$ after PDA closure (P value 0.001) (Table 2) (Figure 3).

The LV end diastolic volume per $\mathrm{m} 2$ decreased non significantly after successful PDA closure, from $55.83 \pm 24.51 \mathrm{ml} / \mathrm{m} 2$ before PDA closure to $51.91 \pm 16.29 \mathrm{ml} / \mathrm{m} 2$ after closure (P value 0.058) (Table 2) (Figure 3).

\section{End Systolic Volume (LVESV):}

The LV end systolic volume showed a nonsignificant increase after successful PDA closure, the mean LVESV before PDA closure was $16.77 \pm 10.37$ $\mathrm{ml}$, which increased to $16.88 \pm 10.38 \mathrm{ml}$ after PDA closure ( $\mathrm{P}$ value 0.775$)$ (Table $2 \&$ figure 3 ).

The LV end systolic volume per $\mathrm{m} 2$ also showed a non-significant increase after successful PDA closure, the mean LVESV/m2 before PDA closure was $22.21 \pm 8.62$ $\mathrm{ml} / \mathrm{m} 2$, which increased to $22.24 \pm 8.46 \mathrm{ml} / \mathrm{m} 2$ after PDA closure (P value of 0.950 ) (Table $2 \&$ figure 3 ).

\section{Ejection Fraction (EF\%):}

The LV Ejection fraction decreased significantly after successful PDA closure, the mean EF before PDA closure was $61.73 \pm 5.49 \%$, which decreased to $57.87 \pm 5.61 \%$ after PDA closure (P value 0.001) (Table 2).

\section{Left atrial diameter (LAD):}

The left atrial diameter decreased significantly after successful PDA closure, the mean LAD before PDA closure was $23.10 \pm 5.60 \mathrm{~mm}$, which decreased to $21.97 \pm 5.18 \mathrm{~mm}$ after PDA closure (P value 0.001) (Table 2).

The left atrial diameter index also showed significant decrease after successful PDA closure, the mean LAD index before PDA closure was $34.35 \pm 7.63$ $\mathrm{mm} / \mathrm{m}^{2}$, which decreased to $32.68 \pm 7.15 \mathrm{~mm} / \mathrm{m}^{2}$ after PDA closure (P value 0.001) (Table 2) (Figure 2).

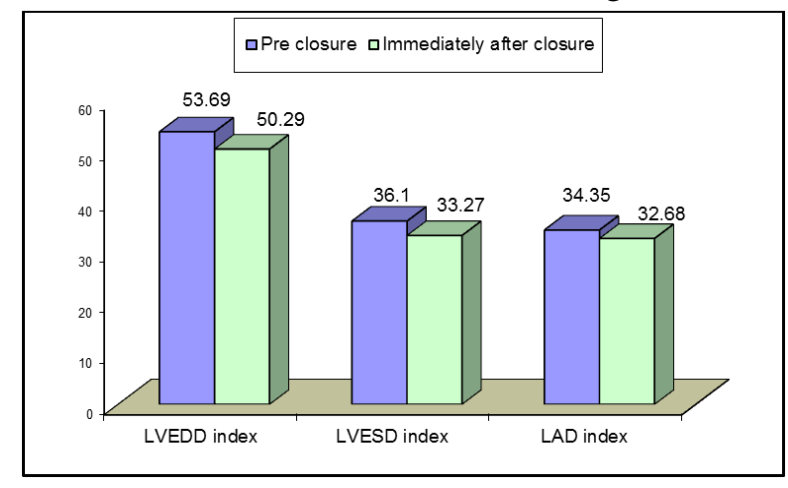

Figure (2): Comparison of LV and LA indexed diameters before and after PDA closure. 


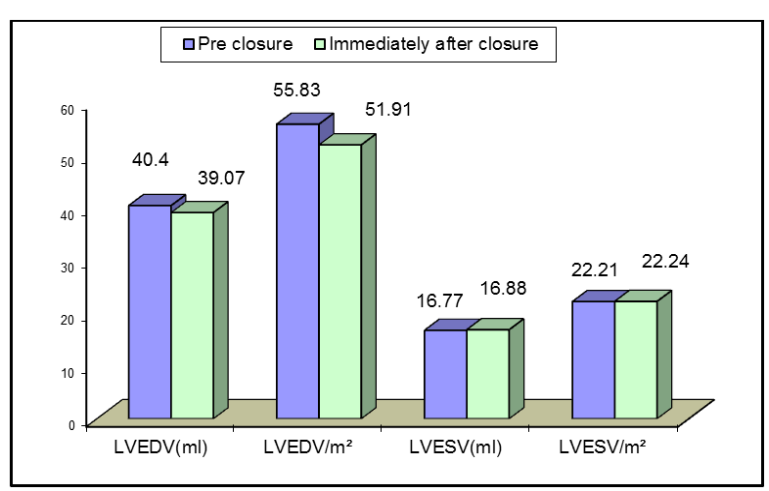

Figure (3): Comparison of LV volumes and volumes $/ \mathrm{m}^{2}$ before and after PDA closure.

Echocardiographic assessment of the left ventricular function using tissue Doppler imaging and myocardial performance index before and immediately after PDA closure:

TDI velocities of interventricular septum at medial mitral valve annulus:

The septal $S$ velocity decreased significantly after successful PDA closure, the mean septal S velocity before PDA closure was $7.89 \pm 2.15$ $\mathrm{cm} /$ second which decreased to $6.32 \pm 1.32 \mathrm{~cm} / \mathrm{s}$ after PDA closure (P value 0.001).

The septal $E^{\prime}$ velocity also decreased significantly after successful PDA closure, the mean septal E' velocity before PDA closure was $13.33 \pm$ $3.52 \mathrm{~cm} / \mathrm{second}$ which decreased to $10.53 \pm 2.31$ $\mathrm{cm} / \mathrm{s}$ after PDA closure (P value 0.001$)$.

The septal A velocity decreased significantly after successful PDA closure, the mean septal A velocity before PDA closure was $7.23 \pm$ $3.09 \mathrm{~cm} /$ second which decreased to $5.82 \pm 2.31 \mathrm{~cm} / \mathrm{s}$ after PDA closure (P value 0.001).

The septal E'/A' ratio decreased non significantly after successful PDA closure, the mean septal E'A' ratio before PDA closure was $2.07 \pm$ 0.77 which decreased to $2.06 \pm 0.88$ after PDA closure (P value 0.898 ).

TDI velocities of LV lateral wall at lateral mitral valve annulus:

The lateral S velocity decreased significantly after successful PDA closure, the mean lateral S velocity before PDA closure was $7.48 \pm 1.85$ $\mathrm{cm} /$ second which decreased to $6.59 \pm 2.30 \mathrm{~cm} / \mathrm{s}$ after PDA closure ( $\mathrm{P}$ value 0.039 ).

The lateral E' velocity decreased significantly after successful PDA closure, the mean lateral $E^{\prime}$ velocity before PDA closure was $15.04 \pm$ $4.07 \mathrm{~cm} / \mathrm{second}$ which decreased to $12.30 \pm 3.64$ $\mathrm{cm} / \mathrm{s}$ after PDA closure ( $\mathrm{P}$ value 0.001$)$.
The lateral A' velocity also decreased significantly after successful PDA closure, the mean lateral A' velocity before PDA closure was $6.91 \pm$ $3.56 \mathrm{~cm} / \mathrm{second}$ which decreased to $5.10 \pm 2.14 \mathrm{~cm} / \mathrm{s}$ after PDA closure ( $\mathrm{P}$ value 0.003 ).

The lateral E'/A' ratio increased non significantly after successful PDA closure, the mean lateral E'/A' ratio before PDA closure was $2.62 \pm$ 1.34 which increased to $2.81 \pm 1.36$ after PDA closure (P value 0.449).

MPI (Tei index) calculated before and immediately after PDA closure:

The MPI increased significantly after successful PDA closure, the mean MPI before PDA closure was $0.46 \pm 0.15$ which increased to $0.58 \pm$ 0.15 after PDA closure (P value 0.001 ).

The MPI was increased immediately after PDA closure in 21 patients (70\%). We compared different variables to get a correlation between them and the increase of MPI, the MPI before closure was the only value to be significantly related to the increase of MPI immediately after percutaneous closure of PDA as described in (table 1).

Table (1): Correlation between different patient's characteristics and pre-closure echocardiographic parameters and prolongation of MPI immediately after PDA closure.

\begin{tabular}{|c|c|c|c|c|c|c|}
\hline Drelociume n & mometers & Non Prolonged & Prolonged & oct volun & (n) & \\
\hline & & No. $=9$ & No. $=21$ & & & \\
\hline & Coil & $8(88.9 \%)$ & $15(71.4 \%)$ & & & \\
\hline Type of closure & Device & $1(11.1 \%)$ & $6(28.6 \%)$ & $1.0 / 4 *$ & 0.300 & NS \\
\hline & Median(IQR) & $1.50(0.7-4)$ & $5.00(2.25-9)$ & & & \\
\hline Age in years & Range & $0.6-9$ & $0.75-16$ & $-1.900 \%$ & 0.057 & NS \\
\hline & Mean \pm SD & $0.58 \pm 0.22$ & $0.79 \pm 0.33$ & & & \\
\hline $\operatorname{BSA}\left(\mathrm{m}^{2}\right)$ & Range & $0.36-0.98$ & $0.35-1.6$ & $-1.742 \bullet$ & 0.092 & NS \\
\hline & Mean \pm SD & $2.28 \pm 0.38$ & $2.63 \pm 0.65$ & & & \\
\hline Pulmonary end(mm) & Range & $2-3$ & $1.7-4$ & $-1.483 \bullet$ & 0.149 & NS \\
\hline & Mean \pm SD & $86.56 \pm 17.04$ & $80.90 \pm 18.65$ & & & \\
\hline PPG(mmHg) & Range & $48-100$ & $50-120$ & $0.779 \bullet$ & 0.442 & NS \\
\hline $\mathrm{EF}(\%)$ & Mean \pm SD & $60.33 \pm 5.83$ & $62.33 \pm 5.37$ & -0912 • & 0370 & NS \\
\hline $\mathrm{EF}(\%)$ & Range & $50-66$ & $55-75$ & $-0.912^{\circ}$ & $0.3 / 0$ & INS \\
\hline LVEDD(mm) & Mean \pm SD & $32.22 \pm 5.38$ & $36.90 \pm 7.46$ & $-1.696^{\bullet}$ & 0.101 & NS \\
\hline & Range & $22-38$ & $24-49$ & $-1.090^{\circ}$ & & \\
\hline JVESD indoy & Mean \pm SD & $38.60 \pm 7.64$ & $35.03 \pm 11.93$ & 0370. & 0708 & NS \\
\hline LVESD index & Range & $27.5-52$ & $21.2-75$ & $0.3 / 9^{\circ}$ & 0.108 & INS \\
\hline I VFDV(m) & Mean \pm SD & $49.61 \pm 10.34$ & $58.50 \pm 28.34$ & $1837 \bullet$ & 0.077 & NS \\
\hline LVEDV(mI) & Range & $35-70.6$ & $32.6-167$ & $-1.83 /{ }^{\circ}$ & $0.0 / 7$ & INS \\
\hline LVESV $(\mathrm{ml})$ & Mean \pm SD & $11.72 \pm 5.29$ & $18.93 \pm 11.33$ & $-0.920 \bullet$ & 0365 & NS \\
\hline LVESV(ml) & Range & $4.5-21.5$ & $5-39$ & & & \\
\hline & Mean \pm SD & $0.57 \pm 0.20$ & $0.41 \pm 0.10$ & 3102 • & 0.004 & HS \\
\hline IVIFT & Range & $0.33-0.9$ & $0.3-0.6$ & $0.102^{\circ}$ & 0.004 & חS \\
\hline
\end{tabular}

P-value > 0.05: Non significant; P-value < 0.05: Significant; P-value $<0.01$ : Highly significant

*: Chi-square test; $\bullet$ : Independent t-test; + :

Mann Whitney test

2D and Doppler echocardiographic assessment before and one month after PDA closure:

LV End Diastolic Dimensions (LVEDD): 
The LV end diastolic dimensions decreased significantly after successful PDA closure, the mean LVEDD before PDA closure was $35.50 \pm 7.15 \mathrm{~mm}$ which decreased to $32.77 \pm 7.63 \mathrm{~mm}$ after one month (P value 0.001) (Table 2).

The LV end diastolic dimensions indexed to BSA also decreased significantly after successful PDA closure, the mean LVEDDI decreased from $53.69 \pm 13.44 \mathrm{~mm} / \mathrm{m}^{2}$ before closure to $49.38 \pm 11.80$ $\mathrm{mm} / \mathrm{m}^{2}$ one month after PDA closure (P value 0.001$)$ (Table 2).

LV End Systolic Dimensions (LVESD):

The LV end systolic dimensions decreased after successful PDA closure, the mean LVESD before PDA closure was $23.27 \pm 5.54 \mathrm{~mm}$ which decreased to $22.08 \pm 5.64 \mathrm{~mm}$ one month after PDA closure (P value 0.001) (Table 2).

The LV end systolic dimensions indexed showed a decrease from $36.10 \pm 10.82 \mathrm{~mm} / \mathrm{m}^{2}$ before PDA closure to $32.01 \pm 7.78 \mathrm{~mm} / \mathrm{m}^{2}$ one month after PDA closure (P value 0.018) (Table 2).

LV End Diastolic Volume (LVEDV):

The LV end diastolic volume decreased significantly after successful PDA closure, the mean LVEDV before PDA closure was $40.40 \pm 22.58 \mathrm{ml}$ which decreased to $39.31 \pm 21.57 \mathrm{ml}$ one month after PDA closure (P value 0.002) (Table 2).

The LV end diastolic volume per $\mathrm{m} 2$ showed a non-significant decrease after successful PDA closure, from $55.83 \pm 24.51 \mathrm{ml} / \mathrm{m} 2$ before PDA closure to $53.01 \pm 14.67 \mathrm{ml} / \mathrm{m} 2$ one month after closure (P value 0.247) (Table 2).

LV End Systolic Volume (LVESV):

The LV end systolic volume showed a nonsignificant decrease after successful PDA closure, the mean LVESV before PDA closure was $16.77 \pm 10.37$ $\mathrm{ml}$, which decreased to $16.05 \pm 9.61 \mathrm{ml}$ one month after PDA closure (P value 0.072) (Table 2).

The LV end systolic volume per $\mathrm{m} 2$ also showed a non-significant decrease after successful PDA closure, the mean LVESV/m2 before PDA closure was $22.21 \pm 8.62 \mathrm{ml} / \mathrm{m} 2$, which decreased to $21.27 \pm 7.66 \mathrm{ml} / \mathrm{m} 2$ one month after PDA closure (P value of 0.082) (Table 2).

\section{Ejection Fraction (EF\%):}

The LV Ejection fraction showed a nonsignificant decrease after one month of successful PDA closure, the mean EF before PDA closure was $61.73 \pm$ $5.49 \%$, which decreased to $61.23 \pm 4.90 \%$ one month after PDA closure (P value 0.376) (Table 2).

\section{Left atrial diameter (LAD):}

The left atrial diameter decreased significantly after one month of successful PDA closure, the mean LAD before PDA closure was $23.10 \pm 5.60 \mathrm{~mm}$, which decreased to $21.93 \pm 5.20 \mathrm{~mm}$ one month after PDA closure (P value 0.001) (Table 2).

The left atrial diameter index also showed significant decrease after successful PDA closure, the mean LAD index before PDA closure was $34.35 \pm 7.63$ $\mathrm{mm} / \mathrm{m}^{2}$, which decreased to $32.71 \pm 7.44 \mathrm{~mm} / \mathrm{m}^{2}$ one month after PDA closure (P value 0.001) (Table 2).

Table (2): Comparison between different echocardiographic parameters measured before and immediately after PDA closure.

\begin{tabular}{|l|c|c|c|c|c|}
\hline \multirow{2}{*}{$\begin{array}{c}\text { Echo } \\
\text { Parameters }\end{array}$} & Pre closure & $\begin{array}{c}\text { Immediately } \\
\text { after closure }\end{array}$ & \multirow{2}{*}{ P-value* } & $\begin{array}{c}\text { One month } \\
\text { after closure }\end{array}$ & $\begin{array}{c}\text { P- } \\
\text { value* }\end{array}$ \\
\cline { 2 - 3 } & Mean \pm SD & Mean \pm SD & & Mean \pm SD & \\
\hline EF(\%) & $61.73 \pm 5.49$ & $57.87 \pm 5.61$ & 0.001 & $61.23 \pm 4.90$ & 0.376 \\
\hline LVEDD(mm) & $35.50 \pm 7.15$ & $32.80 \pm 7.07$ & 0.001 & $32.77 \pm 7.63$ & 0.001 \\
\hline LVEDD index & $53.69 \pm 13.44$ & $50.29 \pm 11.24$ & 0.005 & $49.38 \pm 11.80$ & 0.001 \\
\hline LVESD(mm) & $23.27 \pm 5.54$ & $22.50 \pm 5.81$ & 0.001 & $22.08 \pm 5.64$ & 0.001 \\
\hline LVESD index & $36.10 \pm 10.82$ & $33.27 \pm 6.82$ & 0.065 & $32.01 \pm 7.78$ & 0.018 \\
\hline LVEDV $(m l)$ & $40.40 \pm 22.58$ & $39.07 \pm 22.11$ & 0.001 & $39.31 \pm 21.57$ & 0.002 \\
\hline LVEDV/m ${ }^{2}$ & $55.83 \pm 24.51$ & $51.91 \pm 16.29$ & 0.058 & $53.01 \pm 14.67$ & 0.247 \\
\hline LVESV(ml) & $16.77 \pm 10.37$ & $16.88 \pm 10.38$ & 0.775 & $16.05 \pm 9.61$ & 0.072 \\
\hline LVESV/m ${ }^{2}$ & $22.21 \pm 8.62$ & $22.24 \pm 8.46$ & 0.950 & $21.27 \pm 7.66$ & 0.082 \\
\hline LAD(mm) & $23.10 \pm 5.60$ & $21.97 \pm 5.18$ & 0.001 & $21.93 \pm 5.20$ & 0.001 \\
\hline LAD index & $34.35 \pm 7.63$ & $32.68 \pm 7.15$ & 0.001 & $32.71 \pm 7.44$ & 0.001 \\
\hline
\end{tabular}

Echocardiographic assessment of the left ventricular function using tissue Doppler imaging and myocardial performance index before and one month after PDA closure:

TDI velocities of interventricular septum at medial mitral valve annulus:

The septal S velocity decreased significantly after one month of successful PDA closure, the mean septal S velocity before PDA closure was $7.89 \pm 2.15$ $\mathrm{cm} /$ second which decreased to $7.22 \pm 1.91 \mathrm{~cm} / \mathrm{s}$ one month after PDA closure ( $\mathrm{P}$ value 0.002 ).

The septal E' velocity also decreased significantly after successful PDA closure, the mean septal E' velocity before PDA closure was $13.33 \pm$ $3.52 \mathrm{~cm} /$ second which decreased to $11.63 \pm 3.48$ $\mathrm{cm} / \mathrm{s}$ one month after PDA closure (P value 0.001 ).

The septal A' velocity decreased significantly after successful PDA closure, the mean septal A velocity before PDA closure was $7.23 \pm$ $3.09 \mathrm{~cm} /$ second which decreased to $6.27 \pm 2.38 \mathrm{~cm} / \mathrm{s}$ one month after PDA closure (P value 0.037 ).

The septal E'/A' ratio decreased non significantly after successful PDA closure, the mean septal E'/A ratio before PDA closure was $2.07 \pm$ 0.77 which decreased to $2.04 \pm 0.77$ one month after PDA closure (P value 0.644). 


\section{TDI velocities of $L V$ lateral wall at lateral mitral valve annulus:}

The lateral $\mathrm{S}$ velocity decreased non significantly after one month of successful PDA closure, the mean lateral $S$ velocity before PDA closure was 7.48 $\pm 1.85 \mathrm{~cm} / \mathrm{second}$ which decreased to $7.23 \pm 1.45 \mathrm{~cm} / \mathrm{s}$ one month after PDA closure (P value 0.321).

The lateral $E^{\prime}$ velocity decreased significantly after successful PDA closure, the mean lateral E' velocity before PDA closure was $15.04 \pm$ $4.07 \mathrm{~cm} / \mathrm{second}$ which decreased to $13.18 \pm 3.66$ $\mathrm{cm} / \mathrm{s}$ one month after PDA closure (P value 0.008 ).

The lateral A' velocity decreased non significantly after successful PDA closure, the mean lateral A' velocity before PDA closure was $6.91 \pm$ $3.56 \mathrm{~cm} / \mathrm{second}$ which decreased to $6.12 \pm 3.15 \mathrm{~cm} / \mathrm{s}$ one month after PDA closure (P value 0.149).

The lateral E'/A' ratio decreased non significantly after successful PDA closure, the mean lateral E'/A ratio before PDA closure was $2.62 \pm$ 1.34 which decreased to $2.57 \pm 1.30$ one month after PDA closure (P value 0.822$)$.

\section{MPI (Tei index) calculated before and one month after PDA closure:}

The MPI showed non-significant decrease after successful PDA closure, the mean MPI before PDA closure was $0.46 \pm 0.15$ which decreased to $0.43 \pm 0.12$ one month after PDA closure (P value 0.228).

\section{DISCUSSION}

The physiological impact and clinical significance of PDA depend largely on its size and the underlying cardiovascular status of the patient, so patients with large PDA may develop left-sided volume overload and pulmonary hypertension. Hemodynamically significant PDA, once closed, decreases the preload to the LV by abolishing the left to right shunt and increases the afterload by isolating the low resistance pulmonary circulation from LV outflow circulation. This simultaneous reduction in the LV preload and increase in the afterload may lead to LV systolic dysfunction ${ }^{(4)}$. Previous studies have reported an immediate change in LV performance followed by recovery within a few months after successful transcatheter closure of PDAs in children and others studied the incidence and predictors of post-PDA closure changes in LV functions ${ }^{(5,6)}$.

The present study was conducted to evaluate the immediate and short term changes in left ventricular functions and dimensions in children underwent percutaneous closure of PDA using conventional 2D echocardiography and tissue
Doppler imaging. Our study included 30 patients who were referred for trans-catheter closure of PDA in Ain Shams University hospital.

The current study demonstrated an early reduction in LV systolic function immediately after successful PDA closure which was transient, subclinical and didn't render to the need of medical treatment. After one month, this deterioration in LV systolic function started to improve as evidenced by improvement of LVEF, TDI velocities and MPI (Tei index).

As regards the LV dimensions, the LVEDD showed a significant decrease in the mean LVEDD and the mean LVEDD indexed to BSA immediately after successful PDA closure and continued to decrease in the one month follow up after closure but non significantly. These findings are concordant with the studies conducted by Amoogzar et al. ${ }^{(11)} ;$ Agha et al. ${ }^{(7)} ;$ Galal et al. ${ }^{(12)}$; Kim et al. ${ }^{(5)}$ and Gupta et al. ${ }^{(6)}$. These studies reported that LVEDD decreases significantly after PDA closure and continues to decrease further at the onemonth follow up and after longer periods of follow up, up to six months, in some of these studies. The LVESD also showed a significant decrease immediately after PDA closure and continued to decrease at the onemonth follow up, but non significantly. These findings are concordant with the previous study conducted by Gupta et al. ${ }^{(6)}$ which showed a significant decrease of the LVESD at day-1 and at the short term follow up after PDA closure ${ }^{(11)}$. The decrease in LVESD in the short term follow up in our study was concordant with previous studies conducted by Amoogzar et al. ${ }^{(11)}$, Galal et al. ${ }^{(12)}$ and Kim et al. ${ }^{(5)}$. However, these studies showed a non significant increase or no change in LVESD measured immediately after the PDA closure.

Regarding the LV volumes, the LVEDV showed a significant decrease immediately after the PDA closure, then increased non significantly and still less than the pre-closure LVEDV at the one-month follow up. These findings are partially concordant with Gupta et al. ${ }^{(6)}$ who demonstrated an immediate significant decrease in LVEDVI after closure, on the other hand, it showed significant decrease in the short term follow up. The LVESV in our study showed a non significant increase immediately after PDA closure and a significant decrease after one month. Gupta et al. ${ }^{(6)}$ study showed a non significant decrease immediately after closure and a significant decrease after the short term follow up ${ }^{(6)}$.

As regards the LVEF, our study showed a significant decrease in LVEF immediately after the PDA closure which increased significantly after one month, 
however, the LVEF after one month remained lower than the pre-closure status. These findings are concordant with studies conducted by Agha et al. ${ }^{(7)}$ and Galal et al. ${ }^{(12)}$.

Moreover, the studies conducted by Gupta et al. (6) and Amoogzar et al. (11) also showed a significant decrease in LVEF immediately after closure which increased at the short-term follow up to be higher than the pre-closure value.

These changes can be explained by the fact that PDA is associated with the left to right shunt, which increases the LV preload. Based on the Frank-Starling's law, an increase in preload results in stretching of muscle fibers and augmented contractility, while PDA closure results in a sudden drop in LV preload and thus a decrease in muscle fiber stretch and systolic performance. Another rationale for this observation is a sudden increase in the afterload, which is due to abolishing of blood flow through PDA and the lowresistance pulmonary circulation that unmasks the preexisting but unrecognized LV dysfunction ${ }^{(7,12)}$.

In our study, global myocardial function of the LV was assessed using the myocardial performance index (MPI). It showed a significant increase immediately after PDA closure which reflects the subtle LV systolic dysfunction. MPI returned to a lower value after one month than that of the pre-closure state. Few studies have measured the MPI to rule out the LV function changes after PDA closure. Our results agreed with those of Agha et al. (7) and Noori et al. (16) who reported a significant increase of MPI immediately after PDA closure that normalized after one month. These changes denote immediate and transient LV myocardial dysfunction following transcatheter ductal closure. As the MPI is inversely related to global myocardial function, an increase in the MPI indicated a deterioration of cardiac function. However, the LV MPI began to normalize even though the loading conditions remained unchanged. Therefore, although a sudden decrease in preload immediately after closure likely contributed to the increase in the LV MPI, the data suggest that transient deterioration in global cardiac function also occurred, possibly due to the acute decrease in myocyte fiber length after the sudden decrease in LV loading volume ${ }^{(7)}$. In current study we further evaluated the correlation between different patient's characteristics and echocardiographic findings in the pre-closure status with the changes in MPI that occurred immediately after closure. We found that the pre-closure MPI is the only significant determinant to predict the post-closure prolongation of the MPI. In the current study, 70\% ( $\mathrm{n}=21)$ had a significant prolongation in the MPI in contrast to a non significant change in $30 \%(\mathrm{n}=9)$. None of the suggested variables (body surface area, age, PDA pulmonary end diameter, PPG across the PDA, preclosure EF, LVEDD, LVESD, LVEDV nor LVESV) showed a correlation with the prolonged MPI postclosure. Agha et al. ${ }^{(7)}$ demonstrated that patients with a significant change in the MPI had a younger age and a prolonged baseline MPI ${ }^{(7)}$.

Tissue Doppler imaging (TDI) of the septal and lateral mitral annular velocities were recorded in this study and showed a significant decrease of all velocities immediately after PDA closure. At one month follow up, septal S velocity as well as lateral $E^{\prime}$ and $A^{\prime}$ increased significantly, whereas, septal E', $\mathrm{A}^{\prime}$ and lateral $\mathrm{S}$ showed non significant increase, denoting improvement of the myocardial function. The E/A' ratios showed a non significant changes along the study. These results partially agreed with those of Agha et al. ${ }^{(7)}$ who reported a significant decline of all tissue Doppler velocities as well as E/A ratio immediately after PDA closure, which were reverted at 1 month ${ }^{(7)}$. On the other hand, Amoogzar et al. ${ }^{(11)}$ study showed no significant change in septal or lateral mitral annular peak systolic velocities (S) either early or late after PDA closure. It showed significant decrease in septal and lateral mitral annular early diastolic velocity (E') early after 24 hours of PDA closure and an increase in the late follow up. Septal and lateral A' and E'/A` ratio also showed no significant changes (11). Our findings are in accordance with the previously published data by Kim et al. ${ }^{(5)}$ as they demonstrated that the tissue Doppler myocardial velocity was significantly decreased during the systolic and diastolic phases at post-closure and follow-up compared to the preclosure measurements. These findings suggest that an immediate reduction in the preload after PDA closure may lead to decreased myocardial velocity during the systolic phase after the procedure. After preload reduction is accomplished, ventricular remodeling may occur slowly and lead to decreased myocardial velocity during the diastolic phase at follow-up ${ }^{(5)}$. Previous studies have reported similar results; that is, changes in myocardial velocity after closure of a leftto-right shunt using a transcatheter device, which might have a volume reduction effect instead of inducing a real change in the myocardial velocity ${ }^{(5)}$. 


\section{LIMITATIONS AND RECOMMENDATIONS}

This study is a single center study with small sample size that could have hindered the possibility of eliciting small differences in the variables affecting the LV dysfunction. In this study, one month follow up was done. Other studies continued for longer periods; up to six months. This could help us tracking changes in the LV after PDA closure and provide more constructive data. The parameters used for the assessment of LV systolic function, were preload dependent which could affect the interpretation in the post-PDA closure state.

\section{CONCLUSION}

PDA causes LV volume overload that may cause subtle LV systolic dysfunction which becomes unmasked and significant after PDA closure due to suddenly decreased LV preload and increased afterload. PDA closure may cause significant decrease in global LV performance including systolic and diastolic dysfunction which is transient and reversible after few months in most cases. Conventional echocardiographic evaluation in addition to TDI and Tei index immediately after closure may detect the subclinical LV systolic dysfunction by assessment of global myocardial performance and ventricular velocities. Pre-closure MPI may predict the increase of MPI after successful transcatheter PDA closure.

\section{REFERENCES}

1. Goldberg AS and Krasuski RA (2013): Patent ductus arteriosus and coarctation of the aorta. In: Manual of Cardiovascular Medicine. Brian P. Griffin.TOPOL. Fourth edition, Lippincott Williams \& Wilkins, Ohio,pp:527-536.

2. Dice JE and Bhatia J (2007): Patent ductus arteriosus: an overview. J. Pediatr. Pharmacol. Ther., 12:138-146.

3. Schneider DJ and Moore JW (2006): Patent ductus arteriosus. Circulation, 114: 1873-1882.

4. Park YA, Kim NK, Park SJ et al. (2010): Clinical outcome of transcatheter closure of patent ductus arteriosus in small children weighing $10 \mathrm{KG}$. or less. Korean J. Pediatr., 53(12): 1012-1017.

5. Kim YH, Choi HJ, Cho Y et al. (2008). Transient left ventricular dysfunction after percutaneous patent ductus arteriosus closure in children. The Korean Society of Cardiology,38(11): 596-600.
6. Gupta SK, Krishnamoorthy KM, Tharakan JA et al. (2011): Percutaneous closure of patent ductus arteriosus in children: Immediate and short-term changes in left ventricular systolic and diastolic function. Ann. Pediatr. Cardiol., 4(2): 139-144.

7. Agha H, Hamza H, Kotby A et al. (2017): Predictors of transient left ventricular dysfunction following transcatheter patent ductus arteriosus closure in pediatric age. J. Saudi Heart Assoc., 29: 244-251.

8. Arlettaz R (2017): Echocardiographic evaluation of patent ductus arteriosus in preterm infants. Front. Pediatr., 5: 147-154.

9. Bokiniec $\mathbf{R}$, Własienko $\mathbf{P}$, BorszewskaKornacka MK et al. (2016): Myocardial performance index (Tei index) in term and preterm neonates during the neonatal period. Kardiol. Pol., 74(9): 1002-1009.

10. Alsafi $Z$, Malmgren A, Gudmundsson $P$ et al. (2017): Myocardial performance index in female athletes. Cardiovascular Ultrasound Journal, 15: 15: 20.

11. Amoogzar H, Salehi S, Farhadi $P$ et al. (2016): Follow-Up Results of Device Occlusion of Patent Ductus Arteriosus. Iran J Pediatr., 26(3): e3621.

12. Galal MO, Amin M, Hussein A et al. (2005): Left Ventricular Dysfunction after Closure of Large Patent Ductus Arteriosus. Asian Cardiovascular and Thoracic Annals, 13: 123-126.

13. Coceani F (2014): Therapeutic manipulation of the ductus arteriosus: current options and future prospects. Journal of the Polish Society of Internal Medicine, 124: 1-2.

14. Gulack BC, Laughon MM, Clark RH et al. (2015): Comparative effectiveness and safety of indomethacin versus ibuprofen for the treatment of patent ductus arteriosus. Early Human Development Journal, 91(12): 725-729.

15. Tripathi A, Black GB, Mark YM et al. (2013): Prevalence and Management of Patent Ductus Arteriosus in a Pediatric Medicaid Cohort. Clin. Cardiol., 36:502-506.

16. Noori S, Friedlich P, Seri I et al. (2007): Changes in Myocardial Function and Hemodynamics after Ligation of the Ductus Arteriosus in Preterm Infants. J Pediatr., 150: 597-602. 